\title{
PREFACE TO THE 1980 EDITION
}

Of the several books that I have written Python has given me most pleasure and satisfaction, and so I am happy to see it appear in paperbound form. Paperbound publication would seem to mean that a scholarly book has met with sufficient approval among educated readers and that its central thesis has stood the test of time.

My method of myth study is thematic. It has met objections, but it seems to me the only method that can be used to show the genetic relationship of several myths to one another and the descent of each with modifications from a common original. It is a kind of structural method, although not Lévi-Straussian. Historical evidence and other methods may supplement it, but this method is indispensable. A single theme may appear spontaneously in several places; a pattern of themes must have a single origin.

The reader should not suppose that the theme list on pages 9-1 1 is a "prearranged framework," as one reviewer called it, as though I had drawn it up when I began my study of the combat myth, and had then fitted every myth to it. In fact, the themes emerged in the course of study, while I was preparing the first eight chapters; and I did not have all forty-three themes until Chapter VIII was written. After completing the book I placed the theme list after the Introduction for readers' convenience, and inserted references to it in the first eight chapters.

Nor should the reader take my remarks on pages $217-218$, as some reviewers have done, to mean that $I$ find the origin of the combat myth in some actual struggle of a prehistoric man with a savage 
beast or brigand. What I say there is that actual combats suggested the central theme of combat. A storyteller could not imagine a combat if nobody had ever fought one. And these remarks should not be combined with those on page 464 concerning the earliest folk narratives: they are not limited to the combat myth, which could have been a myth to begin with. Certainly the reader should not suppose that the process by which the combat myth was developed was repeated in the development of each variant. That would hardly be consistent with a genetic relationship. Each variant is the myth itself, modified in transmission over space and time and affected by local circumstances.

Python reveals the ways of myth, and it is my hope that the paperbound edition will make these known to many more readers.

Berkeley

August 14, 1979

Joseph Fontenrose 